\title{
USO E OCUPAÇ̃̃O DO SOLO DO MUNICÍPIO DE VITÓRIA DA CONQUISTA - BA.
}

Bianca Araújo Santos - biancaaraujo.eng@gmail.com Universidade Estadual do Sudoeste da Bahia - UESB Dimitre Souza de Moura - dimitredm@gmail.com Universidade Estadual do Sudoeste da Bahia - UESB Andrêssa Pereira de Jesus - andressap0803@gmail.com Universidade Estadual do Sudoeste da Bahia - UESB

1. RESUMO: O presente estudo teve por objetivo o mapeamento do uso e ocupação do solo do município de Vitória da Conquista - BA, procurando auxiliar o planejamento ambiental da região, por meio da distribuição do solo em classes de ocupação, utilizando de técnicas de sensoriamento remoto e Sistema de Informação Geográfica (SIG). Foram utilizadas imagens de 30 metros de resolução espacial, com 9 bandas espectrais do sistema sensor TM abordo do satélite Landsat 8, sendo consideradas apenas as 7 primeiras, que foram importadas e georreferenciadas por meio de pontos de controles passíveis de identificação na carta topográfica e na imagem. Os resultados das classes de uso e ocupação do solo foram Vegetação Seca 1163,175 km² (36,29\%), Solo Exposto 960,173 km² (29,96\%), Agricultura/Silvicultura 448,785km² (14,00\%), Floresta 320,154 km²(9,99\%), Área Queimada 156,664 km² (4,89\%) e Área Urbana $156,042 \mathrm{~km}^{2}(4,87 \%)$. Diante o exposto nos resultados, pôde-se concluir que a classe que apresentou maior predominância está relacionada ao período de seca vigente na região e, ainda, que as técnicas de Sensoriamento Remoto demonstraram ser uma ferramenta importante para a análise da dinâmica espacial dos municípios.

Palavras-chave: Sensoriamento remoto, uso do solo, LANDSAT.

\section{INTRODUÇÃO / OBJETIVO}

As técnicas de Sensoriamento Remoto vêm sendo cada vez mais utilizadas em estudos, monitoramentos e pesquisas, o que a promove como ferramenta de ampla utilização em diferentes ramos da ciência. Segundo Kalaf (2013), suas imagens polissêmicas e recursos para realizar levantamentos periódicos permitem a aplicação em diferentes temáticas e o monitoramento de fenômenos dinâmicos e mudanças terrestres. 
Tendo em vista a sua aplicabilidade, o Sensoriamento Remoto (SR) apresenta-se como ferramenta de grande relevância no que se refere ao processo de mapeamento, além de permitir, de forma eficaz, gerar novas leituras e interpretações espaciais, contando com o avanço de tecnologias de ponta, que tem propiciado a apreensão de dados espacializados. Sensores ativos e passivos apresentam particularidades, pois, são capazes de adquirir dados, bastante detalhados, sobre o alvo imageado (LAURO, 2015).

Nesse sentido, a utilização destas geotecnologias vem evoluindo de forma significativa nos últimos anos, abrangendo diferentes organizações nas áreas de administração municipal, infra-estrutura, gestão ambiental, educação, entre outras (KALISKI, 2010).

De acordo Alves (2015), a importância da análise do uso e da ocupação do solo em estudos de distinção ambiental justifica-se especialmente pela necessidade da identificação de fontes ou potenciais fontes de alterações do ambiente.

As classificações iniciais de uso da terra baseavam-se em trabalhos de campo. Contudo, a partir da ascensão das imagens orbitais na década de 70, por meio da plataforma LANDSAT, o mapeamento do uso e ocupação do solo ganhava mais uma importante ferramenta como auxílio (ALVES, 2015).

Ao se analisar a urbanização da cidade de Vitória da Conquista, localizada na Região Sudoeste da Bahia, percebesse que o processo é similar aos das demais cidades médias brasileiras, com a expansão urbana acontecendo de forma acelerada, verificando-se uma grande concentração de indústrias, gerando emprego e renda. Porém, essa expansão intensifica a segregação socio-espacial, explícitas na construção e organização seletiva de determinados espaços, com privilegiada rede de equipamentos urbanos, em meio às ocupações sem planejamento em outros espaços (PASSOS, 2015).

Até a década de 40, a economia de Conquista se baseava na pecuária extensiva, e a agricultura local era basicamente de subsistência (OLIVEIRA, 2013). Segundo Jesus (2010), o crescimento econômico do município deu-se, principalmente, a partir da década de 70, devido à expansão cafeeira, notavelmente favorecida pelas condições naturais ao desenvolvimento dessa monocultura, como solos propícios antes ocupados pela pecuária e culturas de subsistência.

Contudo, com a crise da cafeicultura nas últimas décadas, houve um maior incentivo em relação à produção e melhoria da farinha de mandioca, com implantação de um 


\section{Setembro de 2016}

maior número de fábricas (casas de farinha) desse produto no município. É relevante salientar também a importância do cultivo do milho, feijão e de hortaliças no quadro agrícola do município (JESUS, 2010). Atualmente, o município de Vitória da Conquista se encontra fortemente atingida pela expansão da silvicultura de eucalipto.

Diante o exposto, objetivou-se com o presente estudo classificar imagens do satélite Landsat - 8 para elaboração do mapa de uso e ocupação do solo do limite do município de Vitória da Conquista - BA.

\section{METODOLOGIA}

\subsection{Caracterização área de estudo}

O local do presente estudo refere-se ao município de Vitória da Conquista (Figura 1), pertencente à mesorregião Centro Sul Baiana e na microrregião de Vitória da Conquista, município que possui uma população de 318.901 habitantes. Localizado na porção sudoeste do estado da Bahia com coordenadas geográficas de $14^{\circ} 50^{\prime} 53$ de latitude sul e 4050' 19 de longitude oeste, o município possui uma área de 3.204, $993 \mathrm{Km}^{2}$ divididos entre a zona rural e urbana.
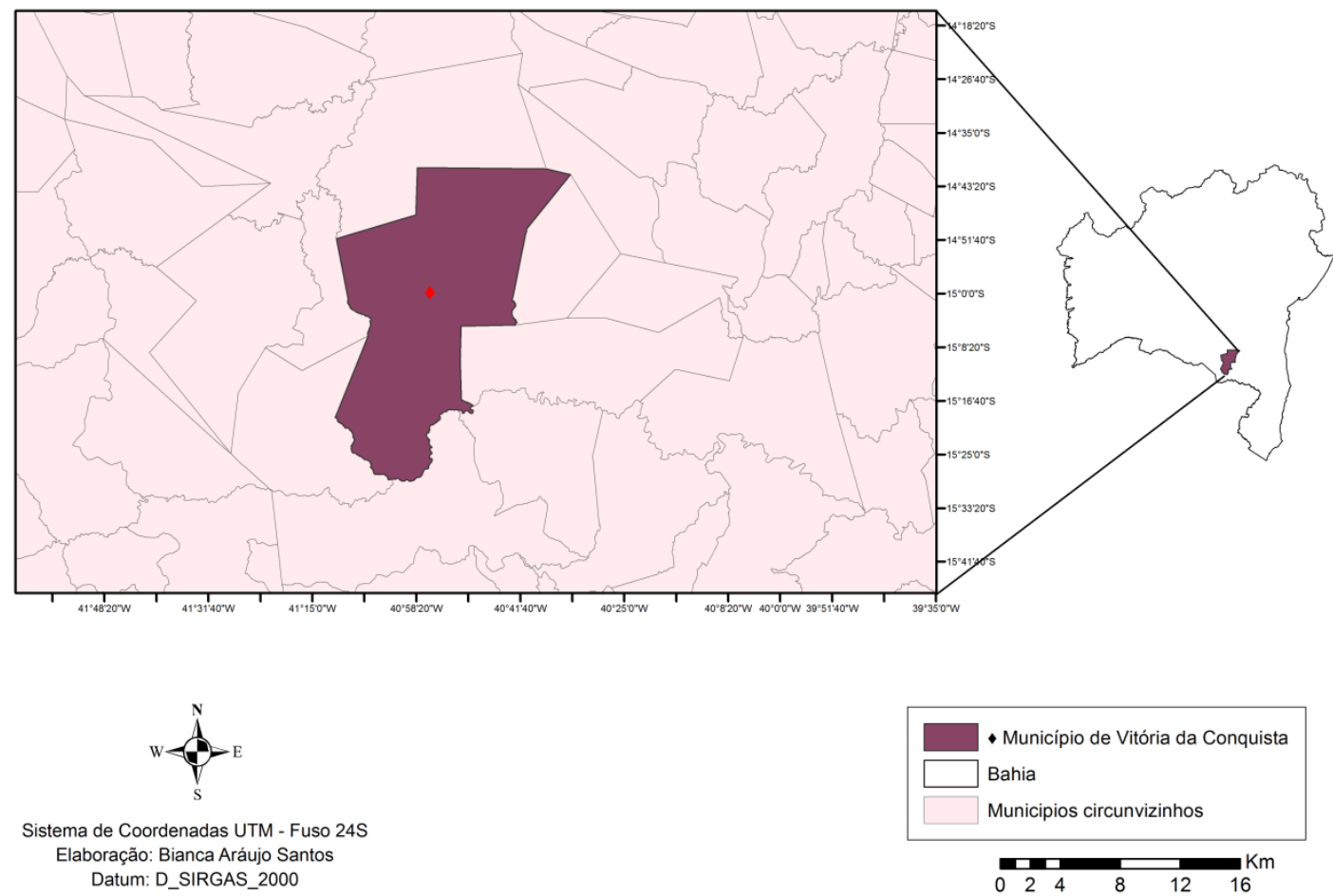

Figura 1. Mapa representativo da localização do município de Vitória da Conquista - BA. Fonte: próprio autor (2016). 
O clima do município é caracterizado como semi-árido e em algumas regiões, subúmido. A temperatura média anual da região é de, aproximadamente, $19,6^{\circ} \mathrm{C}$, sendo o período de maior precipitação de chuvas os meses de novembro a janeiro (JESUS, 2010).

Segundo o levantamento exploratório realizado pela Embrapa, em reconhecimento dos solos no estado da Bahia (Figura 2), os solos da região são caracterizados por: Latossolo Vermelho-Amarelo álico, Latossolo Vermelho-Amarelo eutrófico, Latossolo VermelhoAmarelo Distrófico e Latossolo Vermelho-Escuro eutrófico.

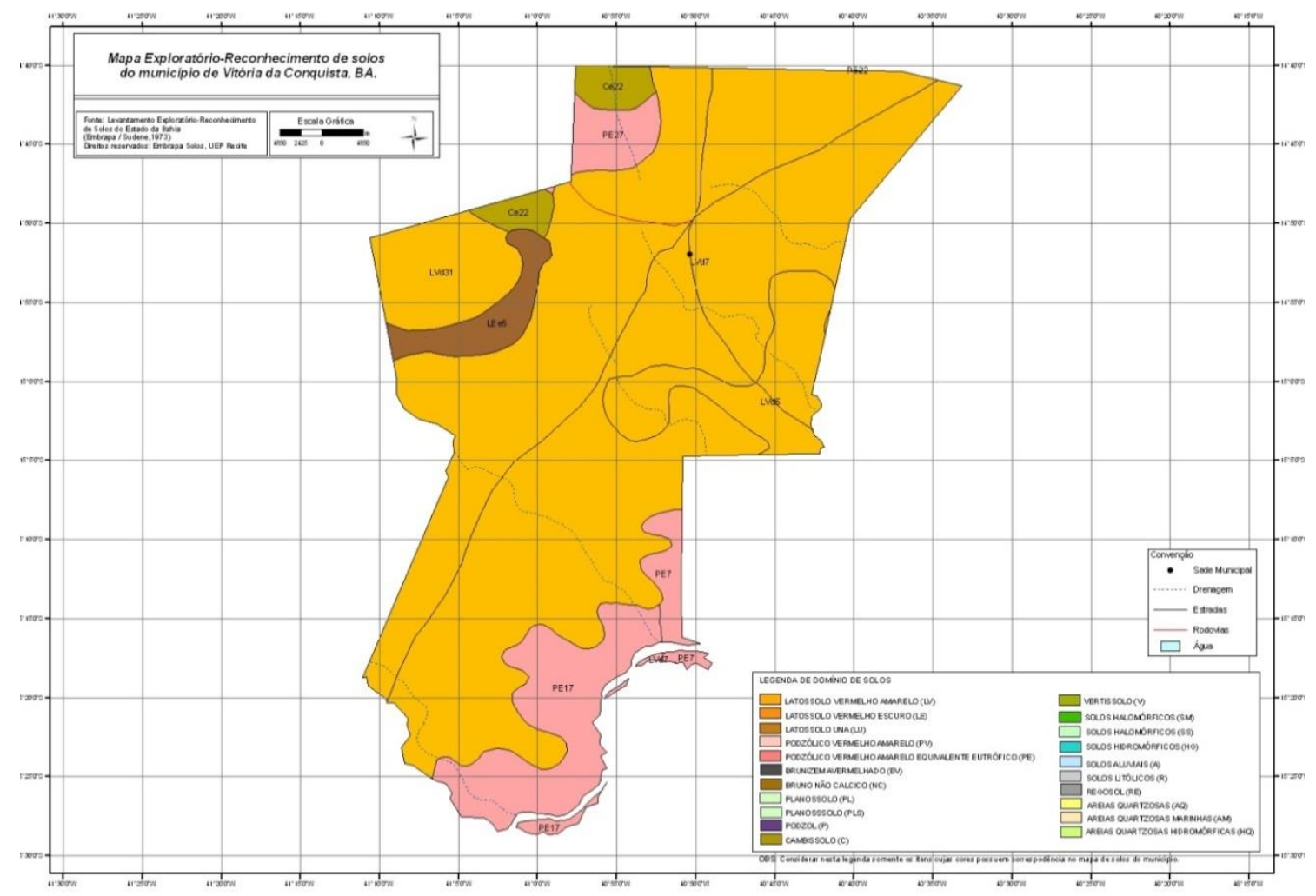

Figura 2 - Mapa Exploratório - Reconhecimento de solos do município de Vitória da Conquista - BA. (Embrapa/SUDENE, 1973) Fonte: http:/www.uep.cnps.embrapa.br/solos/.

Os tipos de solo, clima e geomorfologia da região determinam uma vegetação típica de caatinga, tendo sua área inserida no polígono das secas. Em Vitória da Conquista, ocorre o predomínio de espécies xerófilas, além do cultivo de algumas monoculturas e da silvicultura de eucaliptos apresentarem relevância sobre a ocupação do solo.

\subsection{Classificação do Uso do Solo}

Inicialmente, imagens de satélite do catálogo disponível pelo sítio eletrônico INPE (Instituto Nacional de Pesquisas Espaciais) foram selecionadas de acordo com as órbitas-ponto 217-070 e 217-071 referentes à região. As imagens possuíam 30 metros 
de resolução espacial com 9 bandas espectrais do sistema sensor TM abordo do satélite Landsat 8, fornecidas pelo Diretório Geral de Imagens - DGI do INPE, considerando apenas as 7 primeiras. A escolha foi realizada mediante a mínima percentagem de nuvens na imagem, sendo escolhida a do dia 10 de Agosto de 2016.

Para o pré-processamento e o próprio processamento das imagens, utilizou-se o software ArcGis 10/ArcMap do ESRI. Desta forma, o pré-processamento realizou-se por meio de correções geométricas, como por exemplo, ao adequar o sistema de projeção e refinar o georreferenciamento das bandas. Em seguida, a classificação da imagem foi realizada de forma supervisionada, ou seja, por meio de dados quantitativos e um conhecimento prévio da área estudada.

Posteriormente, o mapeamento do uso e ocupação do solo, foi realizado através da interpretação visual da forma, tonalidade e comportamento espectral das unidades que formam a composição do município. A classificação só pôde ser executada ao gerar um mosaico das bandas de interesse, no caso, abrangendo as bandas de 1 a 7 , em uma composição de bandas RGB, utilizando a ferramenta Composite Bands, disponível no próprio ArcGIS, permitindo, assim, uma melhor visualização. Cada classe teve uma média de 10 amostras de no mínimo 70 pixels, procurando reduzir ao máximo as imperfeições da imagem.

A composição escolhida foi a RGB 432, referente às cores verdadeiras da imagem, aproximando-se da imagem real. As classes de uso do solo exposto e área urbana apresentaram semelhança espectral, tendo que ser realizada uma digitalização em tela da área compreendida pela área urbana. Amostras das classes do uso do solo referente área urbana, floresta, área queimada, solo exposto, agricultura/silvicultura e vegetação seca foram demarcados por meio de polígonos.

Após coletar as amostras referentes a cada classe temática, foi feita uma análise de homogeneidade das amostras, criando um arquivo de assinatura digital espectral. Finalizando a classificação, realizou-se a extração de dados apenas referentes ao limite do município de Vitória da Conquista, computando a área de feição, procurando, por meio de ferramentas disponibilizadas pelo software, reduzir ao máximo as imperfeições da distribuição da ocupação do solo gerada. 


\section{RESULTADOS}

O mapa de uso da terra, representado pela Figura 3, resultante da interpretação da imagem de satélite LANDSAT 8-TM, mostra como as classes de uso estão distribuídas no município.

As análises mostraram que o município de Vitória da Conquista possui, em grande parte de sua extensão territorial a predominância de Vegetação seca (36,29\%), como evidenciado na Tabela 1.

Esta predominância deve-se principalmente à sua localização. O município localiza-se em uma região de transição de Zona da Mata e Caatinga. O bioma da Caatinga possui um clima caracterizado por altas temperaturas, e a vegetação responde à variação na disponibilidade de água, formando uma fauna bastante diversificada.

A vegetação local possui uma fisionomia secundária da Floresta Estacional Decidual, caracterizada por possuir duas estações climáticas bem marcadas, uma chuvoso e outra seguida por estiagem, vegetação caducifólia (perde a folhagem nos períodos de seca). A representatividade da classe pode ser explicada devido ao dia em que o satélite passou, visto que nos encontramos em um período de seca. Vale ressaltar que esta região tem risco alto a médio de seca, possuindo $100 \%$ de sua área inserida no Polígono das Secas.

Tabela 1: Distribuição do Uso do Solo no município de Vitória da Conquista, em Agosto de 2016. Fonte: a autora (2016).

\begin{tabular}{ccc}
\hline Uso do Solo & Área $\left(\mathbf{k m}^{\mathbf{2}}\right)$ & Área (\%) \\
\hline Área Urbana & 156,042 & 4,87 \\
Área Queimada & 156,664 & 4,89 \\
Floresta & 320,154 & 9,99 \\
Agricultura/Silvicultura & 448,785 & 14,00 \\
Solo Exposto & 960,173 & 29,96 \\
Vegetação Seca & 1163,175 & 36,29 \\
\hline Total & 3204,993 & 100 \\
\hline
\end{tabular}

Outra classe de destaque é a de queimadas (29,96\%). As queimadas são fruto do manejo inadequado do solo, pela adoção de técnicas rudimentares e altamente agressivas ao 


\section{Setembro de 2016}

meio ambiente. Isto pode ser identificado, principalmente, na alternância do uso do solo destinado à pecuária para o cultivo de monoculturas.

Grande parte da área de floresta $(9,99 \%)$ está localizada, próximo a áreas de agricultura/silvicultura (14,00\%). Pode-se constatar que, parte da área floresta deu lugar ao cultivo de monoculturas e a silvicultura do eucalipto, que é frequentemente relacionada a impactos sobre o solo, como empobrecimento e erosão.

As áreas de solo exposto $(4,89 \%)$ compreenderam apenas pequenos fragmentos no mapa, totalizando apenas 156,664 $\mathrm{km}^{2}$. Contudo, pode-se identificar a presença do solo exposto por diversas áreas que obtiveram drástica redução da vegetação nativa devido à ação antrópica na abertura de poços e exploração de areia, pedra e outros minérios (bentonita, manganês, quartzo, etc.), resultando na erosão e formação de crateras.

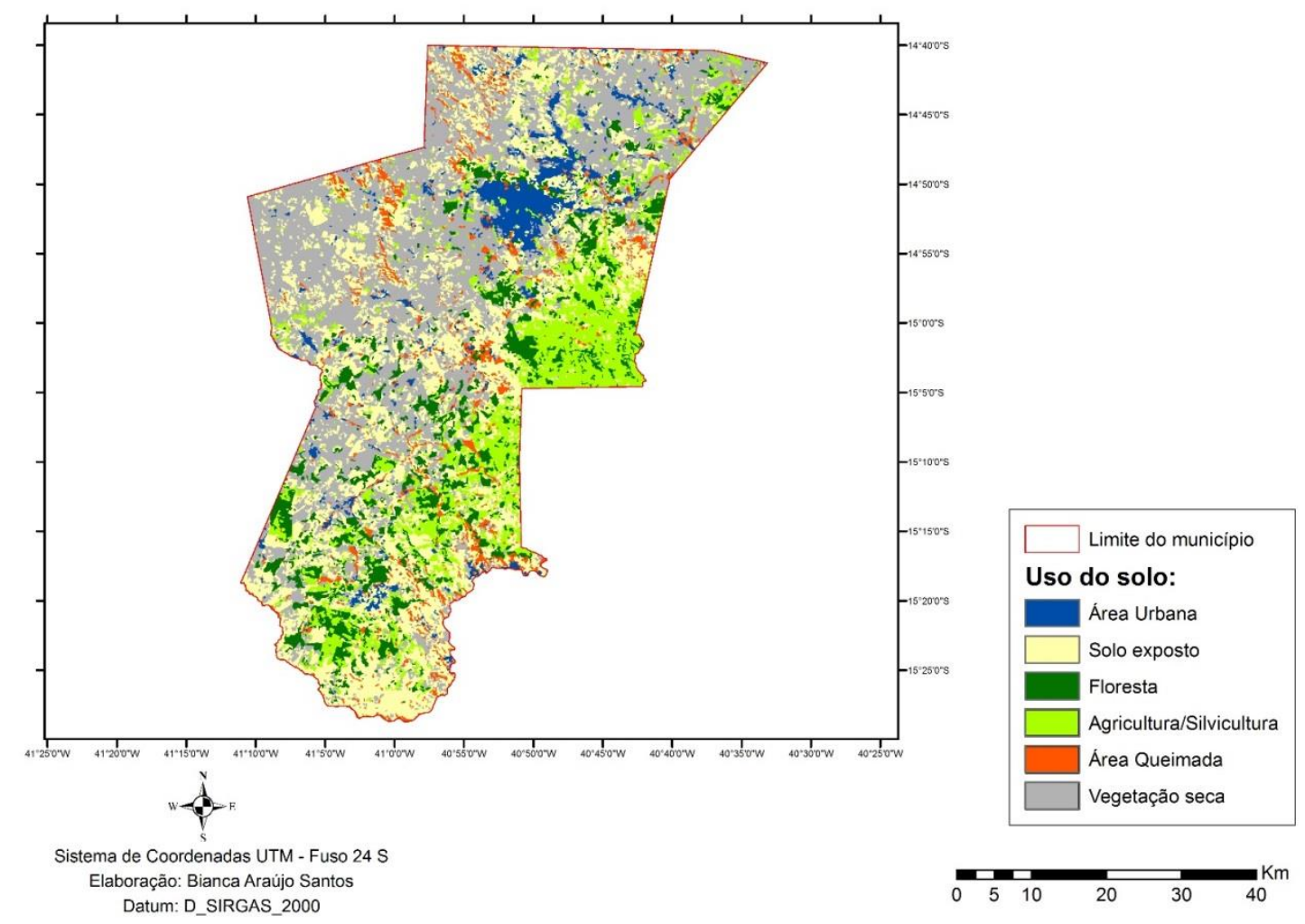

Figura 3. Mapa do Uso do Solo no município de Vitória da Conquista. Fonte: a autora (2016).

A área de menor expansão $(4,87 \%)$ foi a Área Urbana, que embora apresente constante desenvolvimento e ampliação, não ocupa grandes extensões no limite do município de Vitória da Conquista, estando subdivido em pequenos distritos, além da cidade polo. 


\section{CONCLUSÕES}

As técnicas de Sensoriamento Remoto constituíram-se em ferramentas importantes para a análise dos padrões de uso e ocupação do solo do município de Vitória da Conquista. A classe mais representativa entre os diferentes tipos de ocupação foi a Vegetação Seca, com 36,29\% $\left(1163,175 \mathrm{~km}^{2}\right)$ da área do município. Com isso, pode-se concluir que, devido o município ser predominantemente composto por caatinga, o período de seca influenciou de maneira significativa a composição da imagem do satélite.

Solo exposto representa a segunda classe predominante, ocupando 29,96\% (960,173 $\left.\mathrm{km}^{2}\right)$, seguida da Agricultura/Silvicultura que corresponde a 14,00\% $\left(448,785 \mathrm{~km}^{2}\right) \mathrm{da}$ área e Floresta, ocupando 9,99\% da área do município $\left(320,154 \mathrm{~km}^{2}\right)$. As classes de Área Urbana $\left(156,042 \mathrm{~km}^{2}\right)$ e Área de Queimada $\left(156,664 \mathrm{~km}^{2}\right)$ apresentaram a menor predominância, ocupando áreas aproximadas de 4,87\% e 4,89\%, respectivamente.

Diante o exposto no decorrer do estudo, pôde-se concluir que a classificação das imagens orbitais de forma supervisionada contemplou o objetivo de determinar o uso do solo na área de estudo, sendo considerada como elemento crucial para o planejamento ambiental.

\section{REFERÊNCIAS}

ALVES, A.C.; CONCEIÇÃO, P.E.A. Levantamento do uso e ocupação do solo por meio de imagens TM-Landsat-5 e ADS-80 para o município de Manaus/AM. João Pessoa - PB, 2015. 8p. (Anais XVII Simpósio Brasileiro de Sensoriamento Remoto SBSR)

JESUS, R.B. Os recursos naturais e sua exploração na formação territorial do Município de Vitória da Conquista-BA. Enciclopédia Biosfera, v. 6, n. 9, p. 1-13, 2010.

KALAF, R. et al. Landsat 8: Avanços para mapeamento em mesoescala. Anais Cong. Bras. de Geoprocessamento, v. 4, 2013.

KALISKI, A.D. ; FERRER, T.R. ; LAHM, R.A. Análise temporal do uso do solo através de ferramentas de geoprocessamento-estudo de caso: município de Butiá/RS. Para Onde!?, v. 4, n. 2, 2010. 
LAURO, A. D. Análise do uso e ocupação da terra em Vitória da Conquista, Barra do Choça e Planalto: Estudo das transformações socioambientais a partir da implantação da lavoura cafeeira (1970 a 2008). 2015.

OLIVEIRA, D. L. et al. Caracterização do sistema de produção do café em assentamentos de Vitória da Conquista, Bahia. 2013.

PASSOS, J.G.F.G.; GONÇALVEZ, N.M.S. Produção do espaço urbano e requalificação de áreas degradadas: o caso do bairro Santa Cruz, entorno da Lagoa das Bateias, Vitória da Conquista, Bahia. 15p. 2015. 